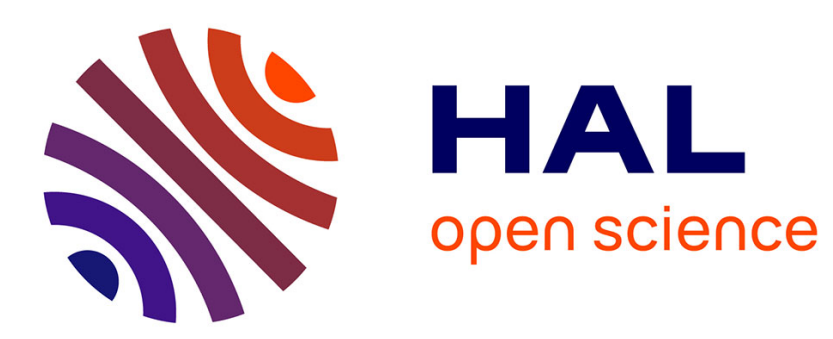

\title{
The effect of LDL apheresis on ocular microcirculation in patients with hypercholesterolemia-A pilot study
}

Naim Terai, Ulrich Julius, Eberhard Spoerl, Michael Haustein, Lutz E Pillunat

\section{To cite this version:}

Naim Terai, Ulrich Julius, Eberhard Spoerl, Michael Haustein, Lutz E Pillunat. The effect of LDL apheresis on ocular microcirculation in patients with hypercholesterolemia-A pilot study. British Journal of Ophthalmology, 2010, 95 (3), pp.401. 10.1136/bjo.2010.180901 . hal-00567052

\section{HAL Id: hal-00567052 https://hal.science/hal-00567052}

Submitted on 18 Feb 2011

HAL is a multi-disciplinary open access archive for the deposit and dissemination of scientific research documents, whether they are published or not. The documents may come from teaching and research institutions in France or abroad, or from public or private research centers.
L'archive ouverte pluridisciplinaire HAL, est destinée au dépôt et à la diffusion de documents scientifiques de niveau recherche, publiés ou non, émanant des établissements d'enseignement et de recherche français ou étrangers, des laboratoires publics ou privés. 
The effect of LDL apheresis on ocular microcirculation in patients with

hypercholesterolemia-A pilot study

\author{
Naim Terai ${ }^{1}$ \\ Ulrich Julius ${ }^{2}$ \\ Michael Haustein $^{1}$ \\ Eberhard Spoerl ${ }^{1}$ \\ Lutz E. Pillunat ${ }^{1}$
}

${ }^{1}$ Department of Ophthalmology

University Hospital Dresden

Fetscherstr. 74

01307 Dresden

Germany
${ }^{2}$ Department of Internal Medicine III University Hospital Dresden

Fetscherstr.74

01307 Dresden

Germany

Corresponding author:

Naim Terai, MD

Department of Ophthalmology

Carl Gustav Carus University Hospital

Fetscherstr. 74

01307 Dresden, Germany

Tel.: +49 3514585091

Fax: +493514584335

E-mail: naim.terai@uniklinikum-dresden.de 


\begin{abstract}
Aim

To investigate the effect of LDL (low density lipoprotein) apheresis on ocular microcirculation in patients with hypercholesterolemia
\end{abstract}

\title{
Methods
}

Six patients with hypercholesterolemia were included in this study. The diameter of retinal vessels was measured continuously with the retinal vessel analyzer (RVA) before and after LDL apheresis. After baseline assessment a monochromatic luminance flicker was applied to evoke retinal vasodilation. Flicker response was then analyzed 50, 70 and $120 \mathrm{sec}$ after baseline measurement. Additionally, cholesterol-, HDL-, LDL- and triglyceride level were obtained to find a possible correlation between retinal vessel diameter changes and lipid metabolism before and after apheresis.

\section{Results}

The mean diameter of the arterioles at baseline was $107.6 \pm 2.1 \mu \mathrm{m}$ and the mean diameter of the venules at baseline was $132.8 \pm 3.2 \mu \mathrm{m}$. The diameter of the arterioles after apheresis increased to $111.2 \pm 2.3 \mu \mathrm{m}$ after $50 \mathrm{sec}$, to $113.2 \pm 2.6 \mu \mathrm{m}$ after $70 \mathrm{sec}$ and to $113.7 \pm 2.6 \mu \mathrm{m}$ after $120 \mathrm{sec}$ showing a trend to statistical significance at all time points $(P=0.046, P=0.028$ and $P=0.028)$. The mean diameter of the venules after apheresis increased to $138.8 \pm 5.9 \mu \mathrm{m}$ after $50 \mathrm{sec}$, to $139.8 \pm 6.3 \mu \mathrm{m}$ after $70 \mathrm{sec}$ and to $141.2 \pm 6.0 \mu \mathrm{m}$ after $120 \mathrm{sec}$ showing a trend to statistical significance at all time points (all $\mathrm{P}=0.028$ ). 


\section{Conclusions}

Changes in retinal vascular calibre seem to be associated with the systemic effect of a single LDL apheresis. Vasodilatation of the arterioles and the venules improved after LDL apheresis indicating an improvement of ocular perfusion in patients with hypercholesterolemia.

\section{Licence for Publication}

The Corresponding Author has the right to grant on behalf of all authors and does grant on behalf of all authors, an exclusive licence (or non exclusive for government employees) on a worldwide basis to the BMJ Publishing Group Ltd and its Licensees to permit this article (if accepted) to be published in BJO editions and any other BMJPGL products to exploit all subsidiary rights, as set out in our licence(http://group.bmj.com/products/journals/instructions-for-authors/licence-forms/)."

Competing Interest: None to declare

Key words: LDL-apheresis, retinal vessel analyzer (RVA), microcirculation 


\section{Introduction}

LDL (low density lipoprotein) apheresis has become a valid treatment modality for patients with severe hypercholesterolemia in whom a maximal dietetic and drug treatment did not lead to a sufficient decrease of LDL-cholesterol (LDL-C) (1). Most patients undergoing this therapy suffer from a manifest coronary heart disease, another atherosclerotic vascular disease (e.g. peripheral arterial disease) or an enhanced risk for retinal vessel occlusions with a consecutive impairment of microand macro-perfusion of end organs. A consequence of the hypercholesterolemiainduced microvascular responses is an enhanced vulnerability of the microcirculation to the effects of ischemia and other inflammatory conditions (2).

Besides LDL lowering effect, a single LDL-apheresis treatment was already reported to positively influence and improve myocardial (3-5) and cerebral blood flow (6).

Other studies demonstrated a substantial reduction of hemorheologically relevant peptides and as a consequence thereof, a reduction of whole blood viscosity and erythrocyte aggregation rate (7-8) contributing to an increase of blood flow by an enhanced release of nitric oxide (NO) from the endothelium (9).

Against this background it seems conceivable that not only the myocardial and the cerebral perfusion is affected by LDL apheresis but also the retinal microcirculation as the retinal vessels mirror the morphology and function of systemic diseases. Therefore, the aim of the present study was to investigate whether LDL apheresis shows an impact on retinal autoregulation in patients with hypercholesterolemia using the retinal vessel analyzer (RVA).

\section{Methods}


Six patients with hypercholesterolemia were included in this study. The study protocol was approved by the ethics committee of Dresden following the declaration of Helsinki. All subjects signed an informed consent before participating in this study. All patients were recruited from the Dresden Apheresis center of the department of internal medicine of the University Hospital Carl Gustav Carus, Dresden and were undergoing LDL apheresis regularly at this center.

\section{LDL apheresis}

LDL apheresis was performed at the LDL-Apheresis center Dresden using one of four available methods which are described elsewhere in detail and which differ with respect to acute relative reductions in LDL cholesterol (1). Briefly, one patient received DALI (Directly absorbs atherogenic lipoproteins, Fresenius Medical Care, St. Wendel, Germany, ADS 4008) treatment, 1 patient received LF (Lipidfiltration, Octo Nova, Cologne, Germany) treatment and four patients received immunoabsorption (IA, Miltenyi, Bergisch-Gladbach, Germany, Life 18). Plasma and serum samples were obtained before and immediately after LDL apheresis for analysis of lipoproteins and triglycerides (HDL, LDL). Clinical chemistry was measured using standard procedures.

\section{Retinal Vessel Analyzer}

Initially (approximately at 8.00 a.m., before LDL apheresis) patients were referred to the department of ophthalmology for retinal vessel imaging using the retinal vessel analyzer (RVA). Patients had to pass an ophthalmic examination including slit-lamp biomicroscopy, indirect funduscopy and measurement of intraocular pressure (IOP) 
with Goldmann applanation tonometry. Patients with glaucoma, age-related macula degeneration, other ocular diseases and previous intraocular surgery were not allowed to participate in this study. After the first retinal imaging, LDL apheresis was performed in the LDL-Apheresis center and at approximately 2.00 p.m. second retinal imaging (after LDL apheresis) was performed. All measurements were undertaken in the right eye after using tropicamid 0.5\% (Mydrum, Ankerpharm) for pupil dilatation according to the following time schedule: After a short resting period to obtain stable hemodynamic conditions, diameter measurements with the RVA were performed. Retinal vessel diameters were continously measured for 352 seconds. Diffuse luminance flickering light was applied consecutively at 50, 70 and 120 seconds. Before and after each flicker period 60 seconds of baseline recordings were scheduled.

Retinal vessel imaging was evaluated with the retinal vessel analyzer (RVA). The RVA is a commercially available system that comprises a fundus camera (Zeiss FF 450, Jena, Germany), a video camera, a high resolution recorder, a real time monitor, and a personal computer with a vessel diameter analyzing software. The RVA allows the precise determination of retinal vessel' s diameter with a time resolution of 25 readings/sec. Retinal irradiance was approximately $220 \mu \mathrm{m} \mathrm{x} \mathrm{cm}{ }^{-2}$, which is approximately 50 times lower than the maximum level allowed for constant illumination of the retina at the wavelengths mentioned below. The system provides excellent reproducibility and sensitivity (10). In the present study, a major temporal artery and vein was studied. Measurement of retinal vessel diameters was taken between 1 and 2 disc diameters from the margin of the optic disc.

\section{Flickering light stimulation}


For flicker stimulation a custom built device was used, stimulating with light flashes at a frequency of $8 \mathrm{~Hz}$. Flicker was generated by focusing the light of a $150 \mathrm{~W}$ halogen light source on a rotating sector disc producing a square wave light pattern with a modulation depth of $100 \%$. Using an optical fibre, flicker stimuli were delivered to the eye through the illumination pathways of the fundus camera by the RVA. The flicker was centered in the macula with an angle of approximately 30 degrees.

A wavelength -separation technique was used to spectrally separate the flicker light from that used to illuminate the fundus. For flicker stimulation, white light in combination with a $550 \mathrm{~nm}$ low pass cut-off filter was used. This ensures that only light with wavelengths below $550 \mathrm{~nm}$ is used for flicker stimulation. To separate the flickering light from the light illuminating the fundus, an interference filter with a center wavelength of $577 \mathrm{~nm}$ and a bandwidth of $10 \mathrm{~nm}$ (Laser components, Olchingen, Germany) was placed in front of the light source of the fundus camera. This window was chosen because in this spectral range the contrast between blood vessels and the surrounding tissue is optimal. A retinal irradiance of approximately $220 \mu \mathrm{Wcm}^{-2}$ was used to achieve optimal fundus images. A second interference filter which exactly matches the one in the illumination pathway is placed in front of the video camera. This ensures that the light used for flicker stimulation does not reach the CCD chip of the video camera but is perceived by the subject under study (11-14).

Statistical analysis

Statistical analysis was performed using the software SPSS (version 15.0). Changes in retinal vessel diameters were expressed as the absolute diameter changes and percent changes over baseline values. Baseline values were calculated as an average of the last 30 seconds before start of the flicker stimulation. Flicker 
response of the 50 seconds flicker period was calculated as an average of the last 10 seconds of stimulation period, for the 70 seconds of the stimulation period as an average of the last 20 seconds of the stimulation period and for the 120 seconds stimulation as an average of the last 30 seconds of the visual stimulation. Due to the small number of patients the non-parametric Wilcoxon test for paired samples was performed. A P $<0.05$ was considered as the level of significance. Due to multiple testing the $P$-value was adjusted according Bonferroni to $P=0.05 / 3$. Data are presented as the mean +/- SD.

\section{Results}

Six patients were included in this study (4 women, 2 men). Mean age of all patients was 60.3 years (range: $46-71$ years).

The mean diameter of the arterioles before apheresis was $107.5 \pm 2.1 \mu \mathrm{m}$ at baseline, $107.7 \pm 1.9 \mu \mathrm{m}$ after $50 \mathrm{sec}, 109.6 \pm 2.1 \mu \mathrm{m}$ after $70 \mathrm{sec}$ and $107.5 \pm 1.9 \mu \mathrm{m}$ after 120 sec. The mean diameter of the arterioles increased after apheresis to $111.2 \pm 2.3 \mu \mathrm{m}$ after $50 \mathrm{sec}(\mathrm{P}=0.046)$, to $113.2 \pm 2.6 \mu \mathrm{m}$ after $70 \mathrm{sec}(\mathrm{P}=0.028)$ and to $113.7 \pm 2.6$ $\mu \mathrm{m}$ after $120 \mathrm{sec}(P=0.028)$ showing a trend to statistical significance at all time points (Fig.1).

The mean diameter of the venules before apheresis was $132.8 \pm 3.2 \mu \mathrm{m}$ at baseline, $133.8 \pm 3.0 \mu \mathrm{m}$ after $50 \mathrm{sec}, 134.0 \pm 2.6 \mu \mathrm{m}$ after $70 \mathrm{sec}$ and $134.2 \pm 2.6 \mu \mathrm{m}$ after 120 sec. The mean diameter of the venules significantly increased after apheresis to $138.8 \pm 5.9 \mu \mathrm{m}$ after $50 \mathrm{sec}(P=0.028)$, to $139.8 \pm 6.3 \mu \mathrm{m}$ after $70 \mathrm{sec}(P=0.028)$ and to $141.2 \pm 6.0 \mu \mathrm{m}$ after $120 \mathrm{sec}(P=0.028)$ showing a trend to statistical significance at all time points (Fig.2). 
Figure 3 shows the overall flicker-induced vasodilatation changes in $\%$ of the arterioles and the venules before and after apheresis revealing statistical significance for the arterioles $(P=0.028)$ and the venules $(P=0.028)$.

Table 1 indicates the lipid and blood pressure changes before and after apheresis which revealed that cholesterol-, HDL-, LDL- and the triglyceride level significantly decreased $(P=0.028)$ after apheresis treatment. Systemic blood pressure (systolic and diastolic) did not any reveal any significant changes $\mathrm{P}=0.197(\mathrm{P}=0.414)$ before and after apheresis. Pulse per minute significantly increased after apheresis $(P=0.038)$.

Correlation analysis of lipid parameters and blood pressure changes and diameter changes of the retinal vessels did not reveal any significant associations (P-values not shown).

\section{Discussion}

The results of the present study clearly demonstrated an improvement of flickerinduced vasodilatation after a single LDL apheresis treatment in the retinal arterioles and in the venules which was statistically significant in the overall vasodilatation response. Our observation showed that a single LDL apheresis led to an increase of retinal blood flow which was well detectable by the flicker response of the retinal vessel analyzer (RVA). To date, previous studies investigating the microcirculation in other organs showed an improvement in coronary flow reserve and thus myocardial perfusion in patients with coronary heart disease, hypercholesterolemia and in heart transplant recipients (15-17) after single apheresis treatment, presumably by improving the NO-and acetylcholine ( $\mathrm{ACH})$-mediated endothelial vasodilatation (5). 
In retinal vessels the vasodilatory response to diffuse luminance flicker stimulation seems to be mediated by endothelial nitric oxide (10), too, indicating that the local production of nitric oxide in the retinal vessels increases after apheresis, leading to an improvement of vasodilatation and retinal endothelial function in these patients. Our finding is supported by observations of Tamai and colleagues who described an increase of endothelium-dependent vasodilatory response in forearm blood flow associated with increased local production of nitric oxide metabolites (19). According to the law of Hagen-Poiseuille, the microcirculation is directly proportional to the product of vascular radius to the power of four and blood pressure divided by the product of viscosity and vessel length (20). As vessel length is rather constant, the three other parameters could theoretically be influenced by LDL apheresis. Different studies reported a substantial reduction of hemorheologically relevant peptides like fibrinogen by up to $60 \%$ by reducing plasma viscosity (by $<20 \%$ ) and erythrocyte/ thrombocyte aggregation (by > $60 \%$ ) and leading to a significant improvement of micro-perfusion in the brain and the skeletal muscle (21-22). The vessel radius is affected by several different factors, some of which are influenced by LDL apheresis. Kojima at al. demonstrated in two patients treated with dextran sulphate adsorption (DSA) an increase of NO-levels using heparin as an anticoagulant (9).

Another major mechanism being proposed to be involved in endothelial dysfunction in patients with hypercholesterolemia is the presence of a large number of circulating inflammatory oxidative stress markers such as inflammatory cytokins, cellular adhesion molecules, acute phase reactants and C-reactive protein (CRP) which are significantly reduced by LDL-apheresis (23-24). Interestingly, in a recent study by Ramunni et al. in 23 patients with nonarteriitic ischemic optic neuropathy three weekly sessions of LDL apheresis resulted in a reduction of circulating markers of 
endothelial dysfunction, and this reduction was correlated to a significant improvement in visual fields (25).

In our study both, arterioles and venules reacted with a vasodilatation to flicker light which was, however, slightly stronger in the venules than in the arterioles. Here, it needs to be noted that the prevalence of hypertension was high among our patients but all patients showed only mild hypertensive funduscopic retinal changes similar to a fundus hypertonicus grade 1 , indicating a well controlled blood pressure. It remains unclear whether these changes of retinal arterial vessels would also have been observed in patients with an uncontrolled hypertensive blood pressure with more prolonged funduscopic hypertensive changes. Moreover, looking at the baseline values of the arteries and venules before and after apheresis showing nearly equal diameters indicates that the effect of LDL apheresis might only be of short duration but can be provoced by flicker light only. To the best of our knowledge, there are no sufficient data dealing with the duration of apheresis therapy on blood perfusion, neither in the cerebrum nor in the skeletal muscle or in the eye. Unfortunately, we also did not perform retinal vessel analysis on these patients after a longer follow-up period after initial apheresis treatment to detect possible long lasting vascular changes.

One major limitation of this study is certainly the number of patients being included in this pilot study. The changes of retinal vessels ' diameter after LDL apheresis showed a trend towards statistical significance. Except from the overall vasodilatation response (Fig.3), a statistical significance could, however, not be obtained, which might be relied to the small number of patients in this pilot study. By increasing the sample size in future studies it is conceivable that the level of the P-value might even more improve and we would obtain more significant results. As a consequence, we were also not able to perform multiple testing to reveal possible associations between 
LDL parameters and vessel' s diameters. Our study was, however, not designed for this outcome analysis, and a larger sample size may be required to investigate these issues.

Secondly, for ethical reasons, we could not justify performing LDL apheresis in healthy control subjects. Therefore, we cannot say whether apheresis also produces hemodynamic effects in the absence of hypercholesterolemia. However, plasma exchange (another procedure that acutely removes LDL), performed for reasons other than hypercholesterolemia, was associated with unmodified cerebral blood flow, as evaluated by the radioactive xenon technique (26).

Thirdly, employing the RVA, only information about vessel diameter and the reactivity of retinal vessels to flicker stimulation was available. However, given that our measures were done in one single artery and vein and not in all visible vessels, our data do not represent total cross-sectional retinal vessel diameters. In extrapolation, for determination of changes in blood flow per se, information about blood velocity would be required. In principle, this information could be gained using laser doppler flowmetry (LDF).

The fourth limitation of our study is that all our patients received LDL apheresis for several years so that our study results may not represent the effects of an early single apheresis nor depict longitudinal changes. However, a previous study by Mellwig and co-workers comparing initial and chronic LDL apheresis therapy in patients with coronary artery disease revealed similar improvements of coronary perfusion after a single apheresis in the two treatment groups (5).

Taking together, for the first time in this pilot study an improvement of flicker-induced vasodilatation of retinal arterioles and venules was detected in patients with hypercholesterolemia after a single LDL apheresis. Our results indicate that ocular 
blood perfusion is substantially affected by the systemic effect of LDL apheresis in patients suffering from hypercholesterolemia. 


\section{References}

1. Julius U, Frind A, Tselmin S, et al. Comparison of different LDL apheresis methods. Expert Rev Cardiovasc Ther 2008; 6: 629-39.

2. Stokes KY, Cooper D, Tailor A, et al. Hypercholesterolemia promotes inflammation and microvascular dysfunction: role of nitric oxide and superoxide. Free Radic Biol Med 2002; 33: 1026-1036.

3. Mellwig KP. Heparin-induced extracorporal low-density lipoprotein precipitation. Ther Apher Dial 2003; 7: 365-369.

4. Mellwig KP, Baller D, Gleichmann U, et al. Improvement of coronary vasodilalation capacity through single LDL apheresis. Artherosclerosis 1998; 139: $173-178$

5. Mellwig KP, van Buuren F, Schmidt HK, et al. Improved coronary vasodilatatory capacity by HELP apheresis: comparing initial and chronic treatment. Ther Apher Dial 2006; 10: 510-517.

6. Rubba P, Faccenda F, Di Somma S, et al.Cerebral blood flow velocity and systemic vascular resistance after acute reduction of low-density lipoprotein in familial hypercholesterolemia. Stroke 1993; 24: 1154-1161.

7. Bosch T, Wendler T, Jaeger BR, et al. Improvement of hemorheology by DALI apheresis: acute effects on plasma viscosity and erythrocyte aggregation in hypercholesterolemic patients. Ther Apher Dial 2001; 5: 372-376.

8. Moriarty PM, Gibson CA, Shih J, et al. Effect of low-density lipoprotein cholesterol apheresis on blood viscosity. Am J Cardiol 2004; 93: 1044-1046

9. Kojima S. Low-density lipoproteins apheresis and changes in plasma components. Ther Apher 2001; 5: 232-238. 
10. Polak K, Dorner GT, Kiss B, et al. Evaluation of the Zeiss retinal vessel analyzer. Br J Ophthalmol 2000; 84: 1285-1290.

11. Vilser W, Riemer T, Bräuer-Burchardt C, et al. Retinal vessel analyzer (RVA)-a new measuring system for examination of local and temporal vessel behaviour. Invest Ophthalmol Vis Sci 1997; 38: 1050.

12. Luksch A, Lasta, Polak K, et al. Twelve-hour reproducibility of retinal and optic nerve blood flow parameters in healthy individuals. Acta Ophthalmol 2009; 87: $875-80$

13. Schmetterer L, Garhofer G. How can blood flow be measured? Surv Ophthalmol 2007; 52: 134-8.

14. Garhöfer G, Zawinka C, Resch H, et al. Reduced response of retinal vessel diameters to flicker stimulation in patients with diabetes. Br J Ophthalmol 2004; 88: 887-91

15. Igarashi K, Tsuji M, Nishimura M, et al. Improvement of endotheliumdependent coronary vasodilation after a single LDL apheresis in patients with hypercholesteremia. J Clin Apher 2004; 19: 11-6.

16. Jaeger BR, Bengel FM, Odaka K, et al. Changes in myocardial vasoreactivity after drastic reduction of plasma fibrinogen and cholesterol: a clinical study in long-term heart transplant survivors using positron emission tomography. $\mathrm{J}$ Heart Lung Transplant 2005; 24: 2022-30.

17. Kobayashi K, Yashamita K, Tasaki H, et al. Evaluation of improved coronary flow velocity reserve using transthoracic Doppler echocardiography after single apheresis therapy. Ther Apher Dial 2004; 8: 383-9.

18. Dorner GT, Garhofer G, Kiss B, et al. Nitric oxide regulates retinal vascular tone in humans. Am J Physio Heart Circ Physiol 2003; 285: 631-6. 
19. Tamai $\mathrm{O}$, Matsuoka $\mathrm{H}$, Itabe $\mathrm{H}$, et al. Single LDL apheresis improves endothelium-dependent vasodilataion in hypercholesterolemic humans. Circulation 1997; 95: 76-82.

20. Koziolek MJ, Mueller GA. Impact of LDL apheresis on inflammation and microcirculation. Artherosclerosis 2009; 10: 56-58.

21. Schuff-Werner P, Schuetz E, Seyde WC, et al. Improved hemorheology associated with a reduction in plasma fibrinogen and LDL in patients being treated by heparin induced extracorporal LDL precipitation (H.E.L.P). Eur $\mathrm{J}$ Clin Invest 1989; 19: 30-7.

22. Pfefferkorn TK, Knuppel HP, Jaeger BR, et al. Increased cerebral CO2 reactivity after heparin-mediated extracorporal LDL precipitation (H.E.L.P.) in patients with coronary heart disease and hyperlipidemia. Stroke 1999; 30: $1802-6$.

23. Wang Y, Blessing F, Walli AK, et al. Effects of heparin-mediated extracorporal low-density lipoprotein precipitation beyond lowering proatherogenic lipoproteins-reduction of circulating proinflammatory and procoagulatory markers. Artherosclerosis 2004; 175: 145-150.

24. Kojima S, Shida M, Yokoyama H. Changes in C-reactive protein plasma levels during low-density lipoprotein apheresis. Therap Apher Dial 2003; 7: 431-434.

25. Ramunni A, Ranieri G, Giancipoli G, et al. Is the efficiacy of LDL apheresis in ischemic optic neuropathy linked to a reduction in endothelial activation markers? Blood Purif 2006; 24: 405-12.

26. Brown MM, Marshall J. Effect of plasma exchange on blood viscosity and cerebral blood flow. Br Med J 1982; 284: 1733-1736. 


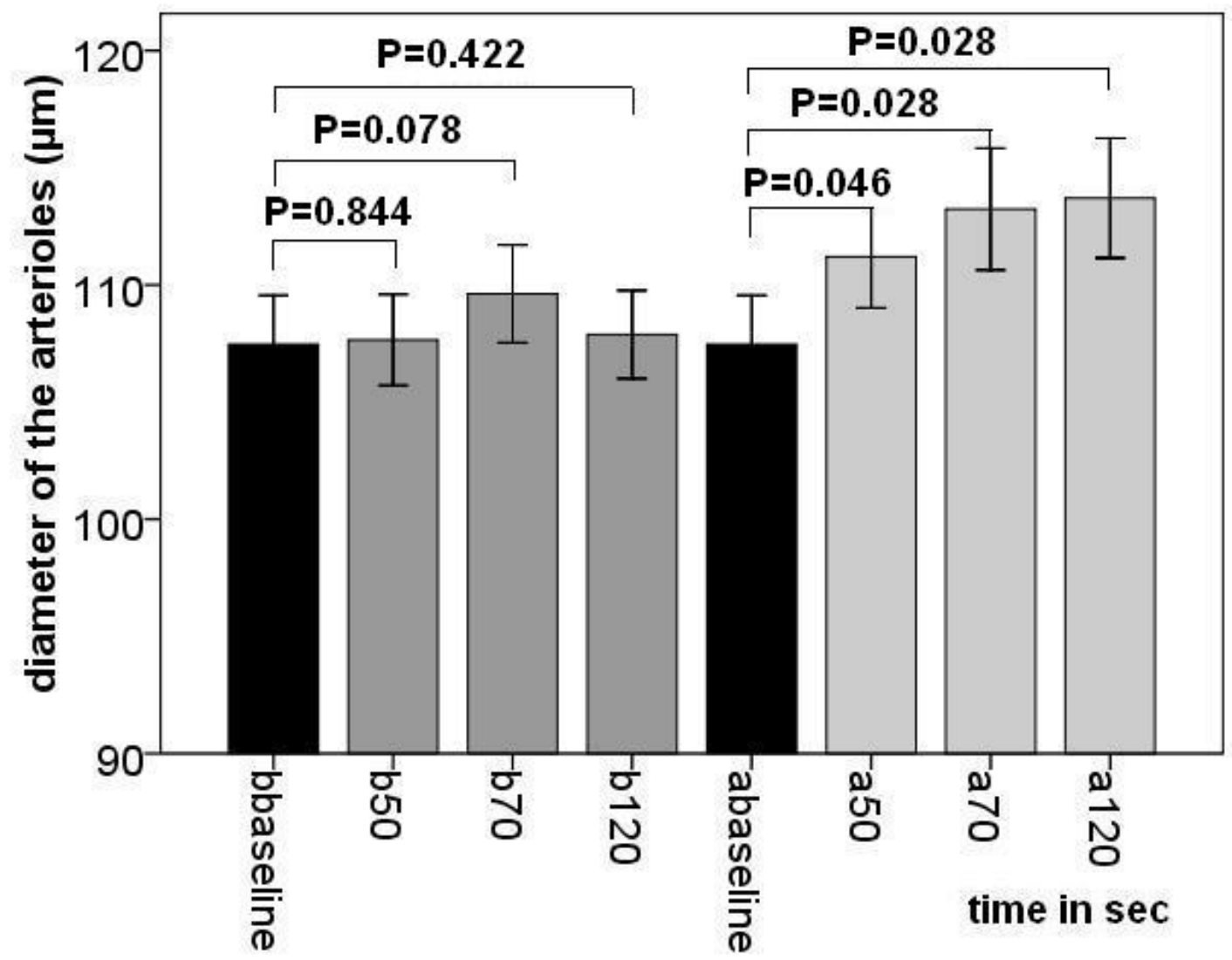

Figure 1 Diameter changes of the arterioles $(\mu \mathrm{m}) \underline{\text { before }}$ LDL apheresis at baseline (bbaseline), after $50 \mathrm{sec}$ (b50), after $70 \mathrm{sec}$ (b70), after $120 \mathrm{sec}$ and after LDL apheresis at baseline (abaseline), after $50 \mathrm{sec}$ (a50), after $70 \mathrm{sec}$ (a70) and after $120 \mathrm{sec}$ (a120) 


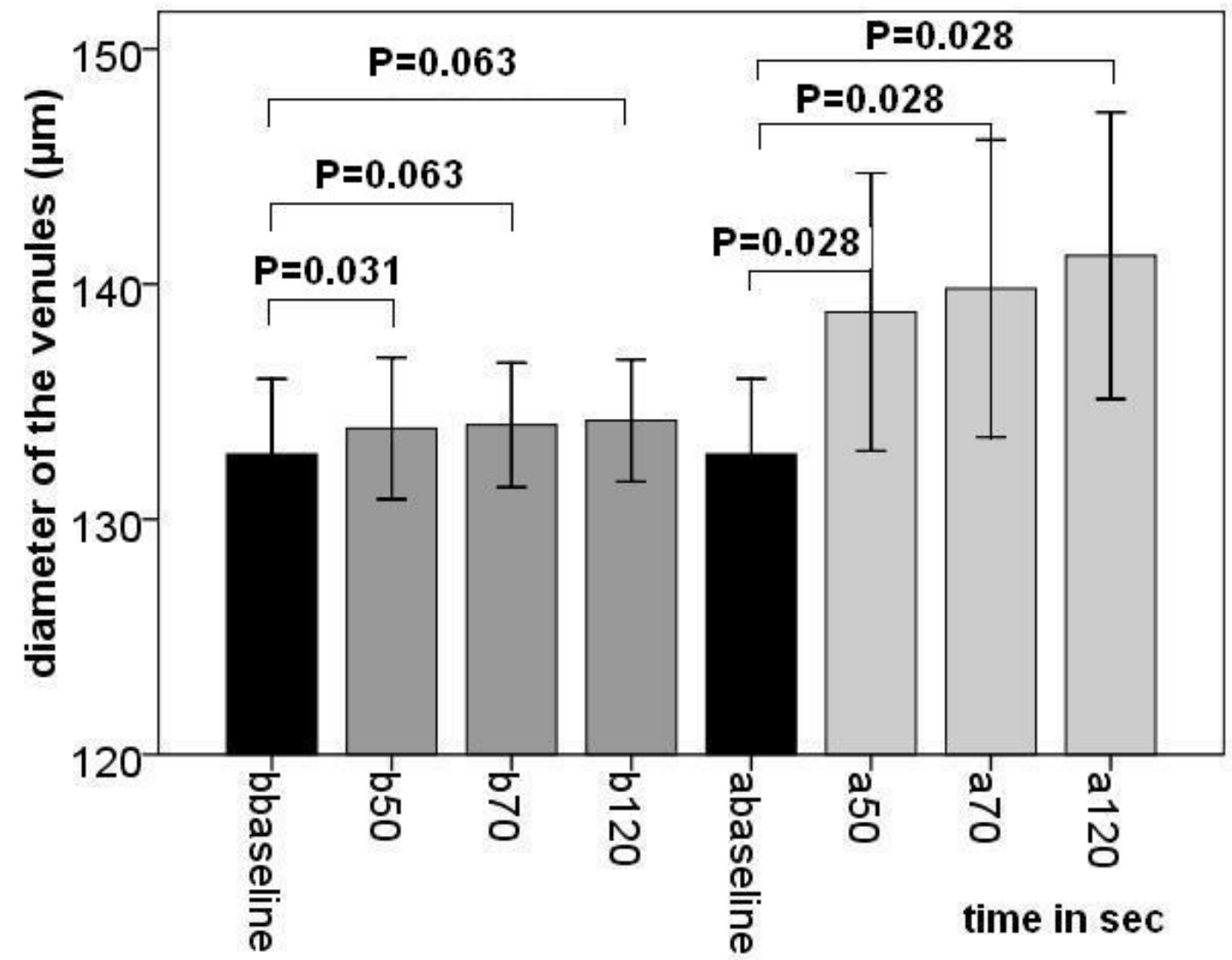

Figure 2 Diameter changes of the venules $(\mu \mathrm{m})$ before LDL apheresis at baseline (bbaseline), after $50 \mathrm{sec}$ (b50), after $70 \mathrm{sec}$ (b70), after $120 \mathrm{sec}$ and after LDL apheresis at baseline (abaseline), after $50 \mathrm{sec}(\mathrm{a} 50)$, after $70 \mathrm{sec}$ (a70) and after $120 \mathrm{sec}(\mathrm{a} 120)$ 


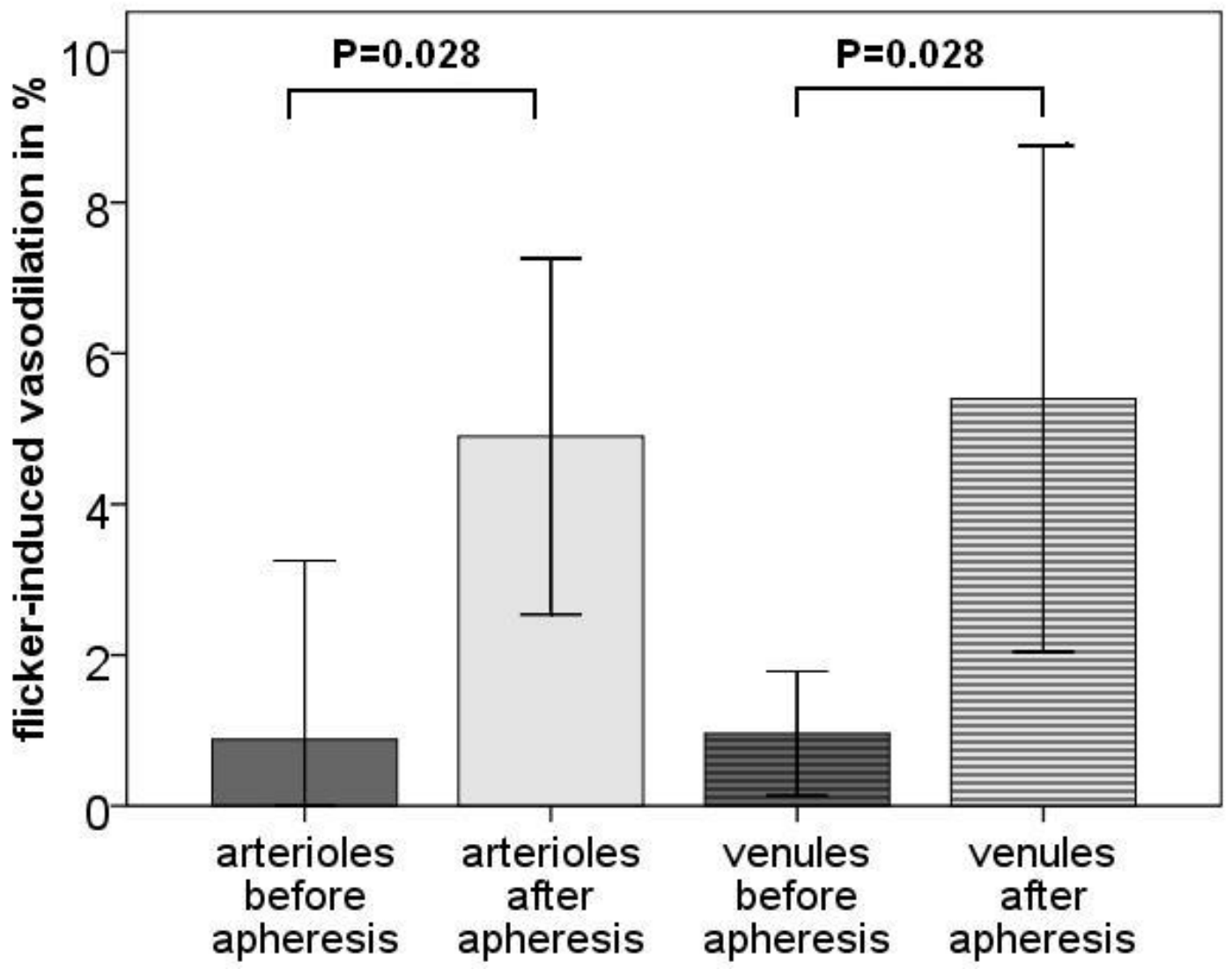

Figure 3 Flicker-induced vasodilatation changes in (\%) in arterioles and venules before and after LDL apheresis 


\begin{tabular}{|c|c|c|c|}
\hline Parameter & Before apheresis & After apheresis & P-Value \\
\hline $\begin{array}{l}\text { Cholesterol } \\
(\mathrm{mmol} / \mathrm{l})\end{array}$ & $4.1 \pm 1.6$ & $2.1 \pm 0.7$ & 0.028 \\
\hline HDL (mmol/l) & $1.5 \pm 0.6$ & $1.1 \pm 0.5$ & 0.028 \\
\hline LDL (mmol/l) & $3.2 \pm 1.4$ & $0.8 \pm 0.3$ & 0.028 \\
\hline $\begin{array}{l}\text { Trigycerides } \\
(\mathrm{mmol} / \mathrm{l})\end{array}$ & $1.8 \pm 0.9$ & $0.9 \pm 0.6$ & 0.028 \\
\hline RRsyst (mmHg) & $135 \pm 17.3$ & $125.8 \pm 27.1$ & 0.197 \\
\hline RRdiast (mmHg) & $79.2 \pm 8.0$ & $76.6 \pm 8.2$ & 0.414 \\
\hline Pulse $\left(\mathrm{min}^{-1}\right)$ & $65.3 \pm 6.0$ & $70.0 \pm 7.4$ & 0.038 \\
\hline
\end{tabular}

Table 1 Lipid and blood pressure parameters before and after LDL apheresis, (SD) 